\title{
Effects of off-road vehicle tyre ruts on the beach dispersal of green sea turtle Chelonia mydas hatchlings
}

\author{
Jason P. van de Merwe ${ }^{1, *}$, Elizabeth J. West ${ }^{1,3}$, Kamarruddin Ibrahim ${ }^{2,4}$ \\ ${ }^{1}$ Griffith School of Environment and Australian Rivers Institute, Griffith University Gold Coast campus, \\ Queensland 4222, Australia \\ ${ }^{2}$ Turtle and Marine Ecosystems Center, Department of Fisheries Malaysia, Rantau Abang, \\ 23050 Dungun, Terengganu, Malaysia \\ ${ }^{3}$ Present address: frc environmental, PO Box 2363, Wellington Point, Queensland 4160, Australia \\ ${ }^{4}$ Present address: Marine Park Department of Malaysia, Ministry of Natural Resources and Environment, \\ Federal Government Administration Centre, 62502 Putrajaya, Malaysia
}

\begin{abstract}
The use of off-road vehicles (ORVs) on sandy beaches creates ruts in the sand that may interfere with the beach dispersal of sea turtle hatchlings. The present study investigated the influence of simulated ORV ruts of 3 depths $(5,10$ and $15 \mathrm{~cm})$ on the success and speed of green sea turtle Chelonia mydas hatchling dispersal. Almost all hatchlings $(91 \%)$ were unable to traverse a single $15 \mathrm{~cm}$ rut, indicating that ruts of this depth are particularly detrimental to hatchling dispersal. Hatchlings had greater success traversing the 5 and $10 \mathrm{~cm}$ ruts, although they spent 2.6 and 18.6 times longer to get through a single rut, respectively (compared to the flat sand control path). It took progressively longer to get through subsequent ruts, and 99 and $53 \%$ of the hatchlings crawled along the 10 and $5 \mathrm{~cm}$ ruts, respectively, instead of attempting to crawl out of them. It was estimated that if hatchlings had to traverse 100 ORV ruts during dispersal, it would take 1.9 and $25.1 \mathrm{~h}$ for 5 and $10 \mathrm{~cm}$ deep ruts, respectively. The results from the present study indicate that green sea turtle hatchlings would spend considerable time navigating through ORV ruts, even as shallow as $5 \mathrm{~cm}$, resulting in increased exposure to predation, dehydration and energy expenditure during this initial stage of dispersal.
\end{abstract}

KEY WORDS: Tyre ruts $\cdot 4$-wheel drive $\cdot$ Off-road vehicle $\cdot$ ORV $\cdot$ Recreational activity $\cdot$ Nesting $\cdot$ Endangered species $\cdot$ Turtle $\cdot$ Seafinding $\cdot$ Hatchling

\section{INTRODUCTION}

Sea turtle populations are declining worldwide due to increasing interactions with anthropogenic activities. As a result, all sea turtle species (with the exception of the flatback Natator depressus, which is Data Deficient) are listed as Vulnerable, Endangered, or Critically Endangered on the IUCN Red List of Threatened Species (IUCN 2011). The use of off-road vehicles (ORVs) for recreational activities is common on sea turtle nesting beaches around the world. The tyre ruts created by ORV traffic on sea turtle nesting beaches may impede the dispersal of hatchlings, although the extent of this is not well understood. Research into the effects of ORV ruts on the dispersal of hatchlings is therefore paramount in managing and conserving sea turtle populations worldwide.

During nesting seasons, adult female sea turtles crawl up onto the beach at night and bury their eggs below the surface of the sand in the dunes. Following 
approximately 50 to $90 \mathrm{~d}$ of incubation (Miller 1985, Ackerman 1997), the eggs hatch and hatchlings climb slowly to the surface. Generally at night, the hatchlings emerge through the sand surface and run down the beach directly to the ocean to begin offshore dispersal. During this period, hatchlings experience high mortality due to predation from crabs and birds (Stancyk 1982). Predation can be particularly high when hatchlings emerge during daylight hours, when crabs and birds are most active. Hatchlings emerge in a state of energetic frenzy (Dial 1987, Wyneken \& Salmon 1992), using the energy from the residual yolk to fuel emergence from the nest and offshore dispersal (Miller 1985). In fact, hatchlings must survive the first few days of life using only the energy in the residual yolk, as they generally do not feed until they are in the deeper oceanic waters.

The use of ORVs on beaches is a popular recreational activity around the world. Damage that results from ORVs includes geomorphic alterations of the beach and dunes as well as disturbance, injury and death of flora and fauna that use the beach and dune habitats (van der Merwe \& van der Merwe 1991, Schlacher \& Thompson 2007). Sea turtle nests are likely to be well protected from direct impacts of ORV traffic as they are generally well below the surface and higher in the dunes where traffic is less common (Schlacher \& Thompson 2007). However, the ruts created by ORV traffic may impede or trap hatchlings during dispersal (Hosier et al. 1981, Lamont et al. 2002). Extra time spent crawling through ORV ruts on the beach slope may increase exposure to predation, dehydration and energy consumption, which may compromise offshore dispersal.

While ORVs are used on many nesting beaches around the world, the effect this has on hatchling dispersal is not well understood. Previous studies on loggerhead sea turtles Caretta caretta by Hosier et al. (1981) and Lamont et al. (2002) indicate that tyre ruts 10 to $15 \mathrm{~cm}$ deep significantly impede the beach dispersal of hatchlings. However, there is currently no information on the effects of shallow ruts $(<10 \mathrm{~cm})$ on hatchling dispersal, or the compounding effects of crawling through multiple ruts, even though hatchings are likely to encounter multiple ORV ruts of varying depths on the beach run. The present study aims to compare the effects of simulated 5, 10 and $15 \mathrm{~cm}$ deep ORV tyre ruts on the beach dispersal of green sea turtle Chelonia mydas hatchlings. Specifically, we compared the success and speed of hatchlings crawling through 3 consecutive ruts at each of these depths. We also investigated the behaviour of green sea turtle hatchlings once they enter tyre ruts of varying depths (5 and $10 \mathrm{~cm}$ ). This information is critical to modelling and accurately predicting increases in dehydration, energy expenditure and exposure to predation experienced by sea turtle hatchlings that encounter ORV ruts during dispersal.

\section{MATERIALS AND METHODS}

\section{Study site}

The present study was conducted at the $\mathrm{Ma}^{\prime}-$ Daerah Turtle Sanctuary (4³2' 27" N, $103^{\circ} 28^{\prime} 14^{\prime \prime} \mathrm{E}$ ), on the east coast of Terengganu, Peninsular Malaysia (Fig. 1), in July 2006. Approximately, 300 to 700 green sea turtle Chelonia mydas nests are laid at Ma'Daerah each year, the majority of which are relocated into hatcheries that have been in operation at this site since 1999. Previous studies indicated that the hatching and emergence success of nests in the Ma'Daerah hatcheries are similar to natural nests (Schauble et al. 2003). In addition, the condition and performance of hatchlings produced from Ma'Daerah hatcheries are similar to hatchlings emerging from nearby in situ nests (Ibrahim et al. 2004, Schauble et al. 2003). The C. mydas hatchlings from

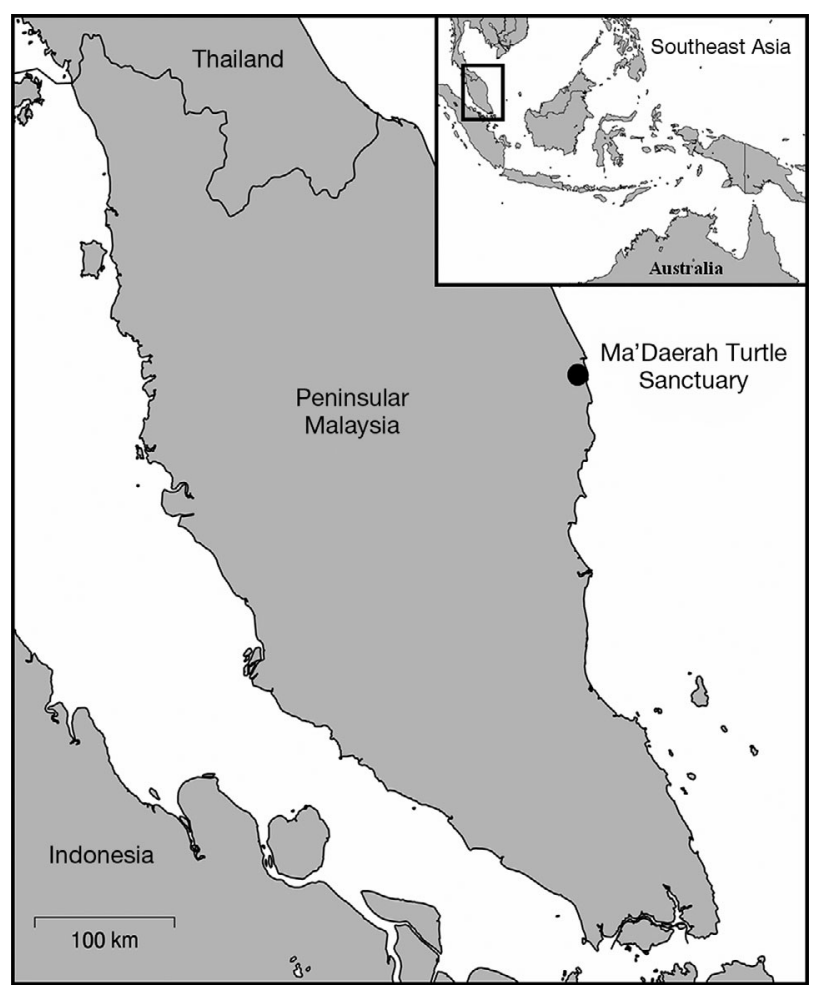

Fig. 1. Location of the Ma'Daerah Turtle Sanctuary where the study was conducted 
the Ma'Daerah hatcheries used in the present study are therefore expected to reflect natural populations.

\section{Hatchling straight-line speed through tyre ruts}

A series of running paths incorporating simulated tyre ruts of 5,10 , or $15 \mathrm{~cm}$ depth were constructed; they were designed to simulate a hatchling encountering 3 consecutive ORV tyre ruts on its dispersal from the nest to the ocean (Fig. 2). For each series, only a single depth was used (i.e. a series of three $5 \mathrm{~cm}$ ruts, a series of three $10 \mathrm{~cm}$ ruts and a series of three $15 \mathrm{~cm}$ ruts). The ruts were constructed parallel to the shoreline, $1 \mathrm{~m}$ apart in the sand on the beach slope. Seawater was used to wet the sand before construction to produce compacted sand that could be easily manipulated into the desired rut shape and size. Ruts were constructed using a piece of plywood that was cut into the cross-section shape of a tyre rut. In brief, the shape was tapered so that the bottom of the rut was slightly narrower than the top of the rut. This resembled the shape of tyre ruts previously measured (J. P. van de Merwe pers. obs.). Two $3 \mathrm{~m}$ wooden planks were then placed parallel, $15 \mathrm{~cm}$ apart, over the top of each of the series of constructed ruts, producing a running path that channelled hatchlings through the 3 consecutive ruts in a straight line. A control path was also constructed which consisted of 2 parallel wooden planks, $15 \mathrm{~cm}$ apart, on the sand surface with no simulated tyre ruts.

Over the sampling period, nests within the Ma'Daerah hatcheries were monitored every $30 \mathrm{~min}$ from 18:00 to 06:00 h so that hatchlings could be collected and tested immediately following emergence. Fifteen hatchlings from each of 19 nests (285 total) were randomly selected and divided equally among the control, 5 and $10 \mathrm{~cm}$ treatments. In addition, 5 hatchlings from each of the first 11 nests (55 total) were collected and allocated to the $15 \mathrm{~cm}$ treatment. The $15 \mathrm{~cm}$ treatment was discontinued after the first 11 nests, due to limited success of hatchlings climbing through this depth. The time taken to crawl through each of the 3 consecutive ruts and the total time to get through all 3 ruts for each treatment was recorded. In order to avoid stress to the hatchlings, if they did not crawl through all 3 ruts within $10 \mathrm{~min}$, they were released onto the sand surface for dispersal. The time taken to crawl through the simulated tyre ruts was measured as an indication of exposure to predation during offshore dispersal.

\section{Hatchling behaviour in tyre ruts}

In a separate experiment, two $6 \mathrm{~m}$ long tyre ruts (5 and $10 \mathrm{~cm}$ deep) were constructed parallel to the shoreline in the damp sand close to the tide mark, using the plywood described above (Fig. 3). Markers were placed at $25 \mathrm{~cm}$ intervals from the centre point of each rut to the north and south ends. Immediately after emergence from hatchery nests, a sample of 10 hatchlings from 12 nests was channelled into the centre of each of these ruts. If hatchlings crawled out of the rut within $10 \mathrm{~min}$, the distance from the centre that hatchlings escaped from was recorded in $25 \mathrm{~cm}$ groups. Hatchlings that did not escape within the 10 min time limit were collected from the ends of the ruts and released onto the beach slope for offshore dispersal.

\section{Statistical analysis}

The time taken to get through the first tyre rut was initially investigated. The mean time for hatchlings to get through the first rut at each depth was calculated for each nest. Hatchlings that took $>10 \mathrm{~min}$ to get

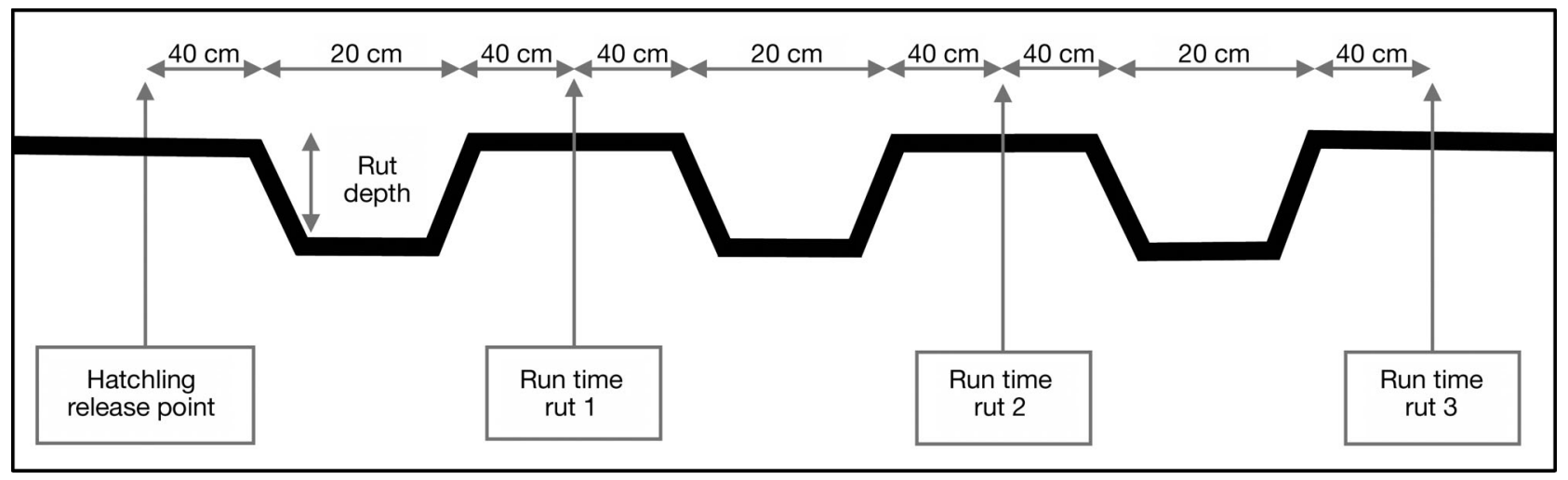

Fig. 2. Cross-section diagram of the tyre rut construction. See 'Materials and methods' 


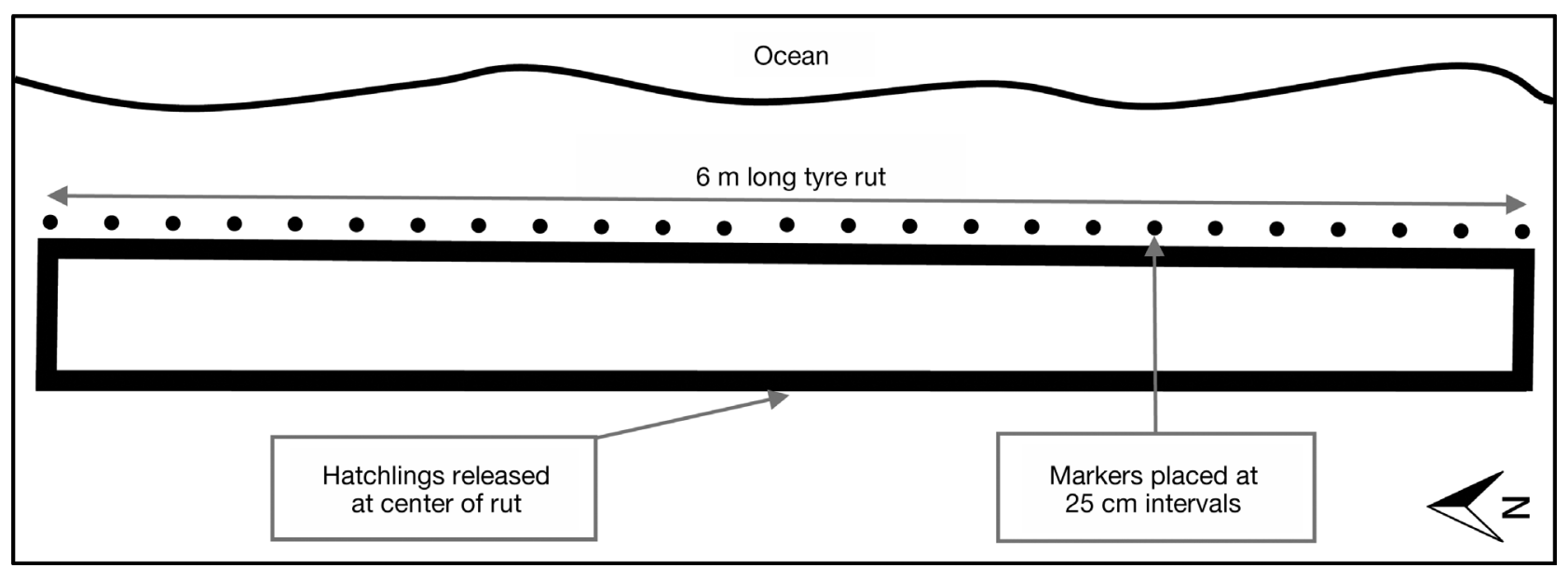

Fig. 3. Top view of the $6 \mathrm{~m}$ tyre ruts created in the sand parallel to the shoreline

through the first rut were excluded from the analyses. A variance components analysis was performed to test how much depth, clutch within depth and hatchling within clutch accounted for the variation in the time taken to get through the first tyre rut. To test the difference in the time taken to get through the first tyre rut of different depths, analysis of variance (ANOVA) was performed on the nest means. If homogeneity of variance was not met (Levene's test: $\mathrm{p}<0.05)$, the data were log transformed and ANOVA was repeated. If ANOVA was significant ( $p<0.05)$, least significant difference (LSD) post hoc was used to test which rut depths were significantly different ( $\mathrm{p}<0.05)$ (Zar 1999).

The effect of having to climb through 3 consecutive tyre ruts was investigated for each rut depth separately using repeated measures ANOVAs. The mean time to get through each of 3 consecutive tyre ruts was calculated for each nest, and only nests where 2 or more hatchlings made it through all 3 ruts were included in these analyses. The Mauchly's test of sphericity (an assumption of repeated measures ANOVA) and Bonferroni post hoc analyses were used to test for differences between subsequent ruts if the repeated measures ANOVA was significant (Zar 1999). Regression analyses were also performed on these data to estimate the time to get through large numbers of consecutive ORV tyre ruts that may occur on turtle nesting beaches. For both the 5 and $10 \mathrm{~cm}$ tracks, linear regressions were performed between the rut number and the mean time to get through each rut. If the regression was significant $(\mathrm{p}<0.05)$ and $\mathrm{R}^{2}>0.90$, the linear equation was used to calculate the time to get through each of 100 ruts. These times were subsequently summed to calculate the cumulative time to traverse 100 consecutive ruts.

\section{RESULTS}

\section{Hatchling straight-line speed through tyre ruts}

All Chelonia mydas hatchlings (95) in the control treatment successfully navigated the running path. Overall, 99 and $57 \%$ of hatchlings made it through all 3 consecutive ruts in the 5 and $10 \mathrm{~cm}$ deep rut series within the $10 \mathrm{~min}$ limit, respectively. Eleven nests (55 hatchlings) were run through the $15 \mathrm{~cm}$ deep ruts, but not a single hatchling made it through the 3 consecutive ruts within the $10 \mathrm{~min}$ limit. In fact only 5 hatchlings $(9 \%)$ made it through a single $15 \mathrm{~cm}$ deep rut within $10 \mathrm{~min}$. Therefore, no further nests were run through the $15 \mathrm{~cm}$ ruts, and these data were removed from the analyses.

All hatchlings made it through the first rut in the $5 \mathrm{~cm}$ simulations. However, a total of 8 hatchlings $(8 \%)$ did not make it through the first $10 \mathrm{~cm}$ rut. Variance components analysis indicated that depth accounted for $88.3 \%$ of the difference in time to get through the first tyre rut, while clutch within depth and hatchlings within clutch accounted for only 4.7 and $7.0 \%$ of the variation, respectively. Of the hatchlings that made it through the first rut, there was a significant difference in the time taken (Fig. 4; ANOVA on log-transformed data: $\mathrm{p}<0.05)$. The time taken increased significantly for each rut depth (LSD: $\mathrm{p}<0.05$ ), and, compared to the controls, hatchlings running through the 5 and $10 \mathrm{~cm}$ deep ruts took 2.6 and 18.6 times longer, respectively (Fig. 4).

The time taken for hatchlings to get through each of the 3 consecutive $5 \mathrm{~cm}$ tyre ruts was not significantly different (Fig. 5; repeated measures ANOVA: $\mathrm{p}=0.84$; Mauchly's test: $\mathrm{p}=0.26$ ). However, for the $10 \mathrm{~cm}$ ruts, hatchlings took significantly longer to get 


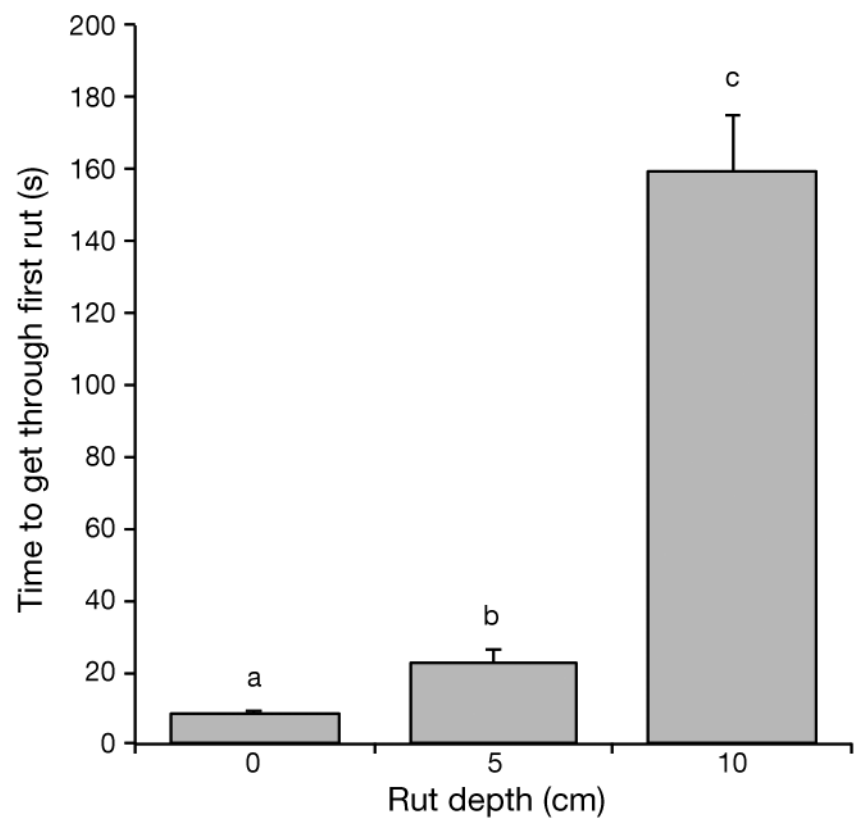

Fig. 4. Chelonia mydas. Mean $( \pm \mathrm{SE})$ time $(\mathrm{s})$ taken for hatchlings to traverse the first tyre rut for 0 (control), 5 and $10 \mathrm{~cm}$ rut depths ( $\mathrm{n}=19$ nests). Only hatchlings that took $<600$ s were included. Different letters indicate significant differences (least significant difference: $\mathrm{p}<0.05$ )

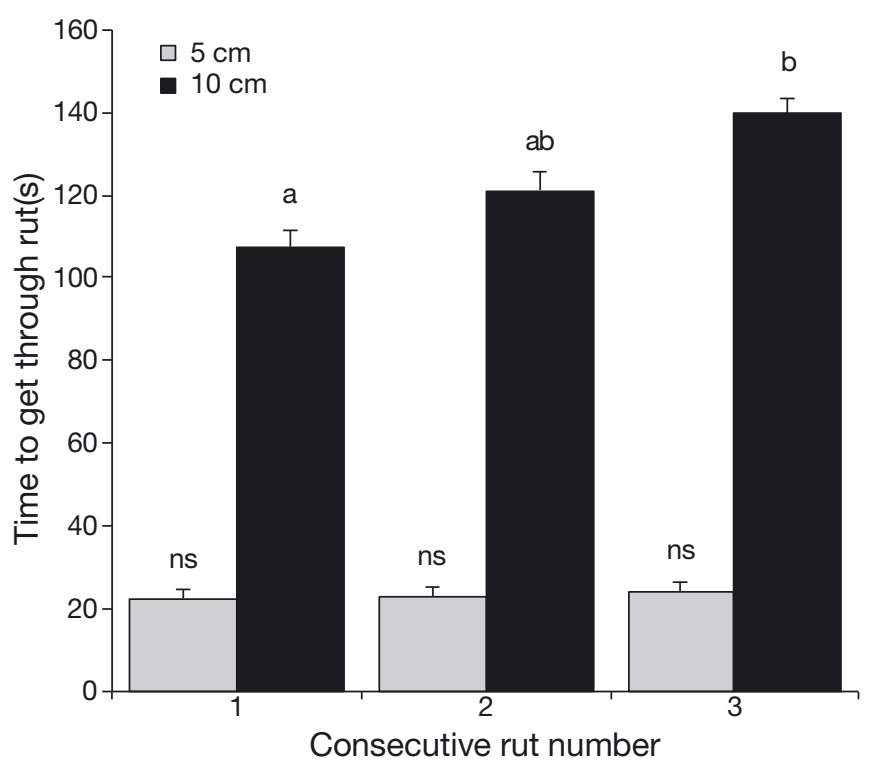

Fig. 5. Chelonia mydas. Mean ( \pm SE) time (s) taken for hatchlings to traverse 3 consecutive tyre ruts of 5 and $10 \mathrm{~cm}$ depths ( $\mathrm{n}=14$ to 19$)$. Only nests where 2 or more hatchlings made it through all 3 tracks were included. Different letters indicate significant difference (least significant difference: $\mathrm{p}<0.05)$. ns: not significant

through the third rut, compared to the first rut (Fig. 5; repeated measures ANOVA: $\mathrm{p}=0.04$; Bonferroni: $\mathrm{p}<$ 0.05; Mauchly's test: $\mathrm{p}=0.86$ ).
Regression analyses indicated linear relationships between the rut number and the mean time taken to get through subsequent ruts: time $=0.91 \times$ rut number $+21.4\left(\mathrm{p}<0.05 ; \mathrm{R}^{2}=0.95\right)$ and time $=16.1 \times$ rut number $+90.6\left(p<0.05 ; R^{2}=0.99\right)$ for 5 and $10 \mathrm{~cm}$ tracks, respectively. Using these equations it was estimated that it would take 1.9 or $25.1 \mathrm{~h}$ for a hatchling to successfully traverse 100 ruts that are all 5 or $10 \mathrm{~cm}$ deep, respectively.

\section{Hatchling behaviour in tyre ruts}

In the $6 \mathrm{~m}$ rut of $5 \mathrm{~cm}$ depth, 56 of the 120 hatchlings $(47 \%)$ crawled out of the rut within the $10 \mathrm{~min}$ time limit (Fig. 6). The majority of these (75\%) escaped from the $5 \mathrm{~cm}$ rut within $1 \mathrm{~m}$ on either side of the centre entry point. In contrast, only 1 hatchling managed to crawl out of the $10 \mathrm{~cm}$ rut, which was $2.75 \mathrm{~m}$ from the centre release point (Fig. 6). Hatchlings that did not escape (53 and $99 \%$ of the 5 and $10 \mathrm{~cm}$ ruts, respectively) ran along the ruts and were collected at the ends $(3 \mathrm{~m}$ from the centre release point) after the $10 \mathrm{~min}$ time limit and released for offshore dispersal.

\section{DISCUSSION}

The results of the present study indicate that the presence of tyre ruts from ORVs on sea turtle nesting beaches may have serious consequences for the dispersal of sea turtle hatchlings. Simulated ORV ruts were found to significantly increase the time taken for hatchlings to disperse, with deeper ruts impeding dispersal completely. These results have implications for the management and conservation of sea turtle populations in areas where the use of ORVs is permitted on nesting beaches during hatchling dispersal seasons.

In the worst-case scenario presented here, the majority of Chelonia mydas hatchlings (91\%) were unable to make it through a single $15 \mathrm{~cm}$ deep rut. This indicated that ORV rut depths of $\geq 15 \mathrm{~cm}$ can completely prevent sea turtle hatchlings from reaching the ocean. It is not uncommon for ORV ruts on sandy beaches to exceed $15 \mathrm{~cm}$. In fact, tyre ruts up to $50 \mathrm{~cm}$ deep have been observed on South Stradbroke Island, southeast Queensland, Australia (van de Merwe \& Cuttriss 2006). Similarly, on North Stradbroke Island a maximum rut depth of $28 \mathrm{~cm}$ was recorded and $21 \%$ of ORV ruts were deeper than $10 \mathrm{~cm}$ (Schlacher \& Thompson 2008). 


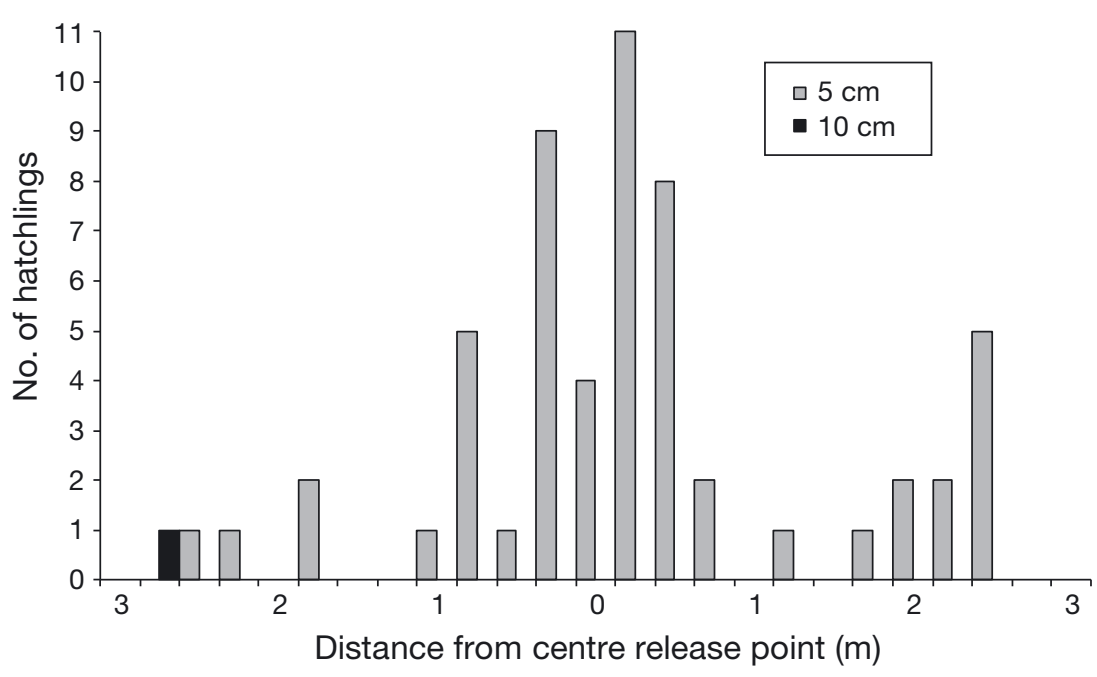

Fig. 6. Chelonia mydas. Total number of hatchlings that escaped from the $6 \mathrm{~m}$ long tyre ruts of 5 and $10 \mathrm{~cm}$ depths within $10 \mathrm{~min}$. Of the 120 hatchlings that were released for each depth, 64 (53\%) and 119 (99\%) hatchlings were unable to escape from the 5 and $10 \mathrm{~cm}$ ruts, respectively, within the allowed time. These hatchlings were collected from the ends of the ruts and released onto the beach for dispersal

Although the green turtle hatchlings in the present study were more successful in climbing through the shallower ruts, they took 2.6 and 18.6 times longer to get through a single 5 and $10 \mathrm{~cm}$ rut, respectively (compared to the flat sand control path). This supports similar findings that pedestrian, tricycle and ORV ruts interfere with the beach run of loggerhead sea turtle Carretta caretta hatchlings (Hosier et al. 1981, Lamont et al. 2002). In North Carolina, loggerhead sea turtle hatchlings subjected to a stretch of beach with ORV ruts were shown to be approximately 1.5 times slower compared to a smooth control beach (Hosier et al. 1981). However, the ability of sea turtle hatchlings to navigate through tyre ruts is likely to be dependent on many biotic (e.g. incubation conditions, hatchling size) and abiotic (e.g. beach slope gradient, weather conditions, sand characteristics) factors.

Hatchlings are likely to encounter multiple consecutive tyre ruts on beaches with ORV traffic. In the present study, although hatchlings traversing 3 consecutive $5 \mathrm{~cm}$ ruts showed similar speeds for all 3 ruts, the regression analyses indicated strong correlation between the rut number and the mean time taken to get through each rut for both depths. It was estimated that hatchlings would take 1.9 and $25.1 \mathrm{~h}$ to successfully crawl through 100 ruts of 5 and $10 \mathrm{~cm}$ depth, respectively. One hundred ruts along the beach slope is not unlikely, given that previous studies on ORV traf- fic have recorded up to 500 ORV passes in a single day (Schlacher \& Thompson 2007), and up to $90 \%$ of the beach rutted with vehicle tracks at a density of 2.38 to 8.06 ruts $\mathrm{m}^{-1}$ (Schlacher \& Thompson 2008).

The extra time taken to crawl through multiple ORV tyre ruts may significantly increase exposure to near-shore predation. Sea turtle hatchlings generally emerge during the night, when shore predation is lowest, and complete their beach dispersal under the relative safety of darkness. The $25 \mathrm{~h}$ estimated to crawl through 100 consecutive $10 \mathrm{~cm}$ ruts would result in significant time spent on the beach during daylight hours, increasing exposure to visual predators such as birds and crabs. In addition, beach dispersal during daylight hours will expose hatchlings to the heat from the sun, which can cause severe dehydration. Even if hatchlings emerge at dusk, the regression analysis indicates that only 68 ruts of $10 \mathrm{~cm}$ depth would be completed before sunrise (assuming approximately $12 \mathrm{~h}$ of night time darkness). Hatchlings emerging within $2 \mathrm{~h}$ of sunrise on beaches with multiple $5 \mathrm{~cm}$ deep ruts would experience similar problems, becoming exposed to predation and heat from the sun during beach dispersal. Even hatchlings emerging closer to dusk on beaches with shallower ORV tyre ruts may experience increased exposure to predation. Although these hatchlings may complete their beach run during the night, the delay caused by crawling through the ORV tyre ruts will reduce the distance travelled under the cover of darkness, and thus is likely to increase exposure to predation in near-shore waters during daylight hours.

The time taken to navigate through ORV ruts can also result in extra consumption of limited energy reserves. Hatchlings generally emerge from nests in a state of energetic frenzy (Dial 1987, Wyneken \& Salmon 1992) and must survive the first few days of dispersal on energy from the residual yolk (Miller 1985). Extra time spent climbing through ORV tyre ruts may result in consumption of critical energy reserves, which may compromise the duration and vigour of offshore dispersal. However, in beaches containing deeper tyre ruts, the exposure to predation and heat from the sun during daylight hours is likely to be far more deleterious to dispersing hatchlings than any losses in energy during this period. 
It should be noted that the estimates of time spent climbing through tyre ruts in the present study are based on hatchlings being channelled in a straight line through the ruts. However, results from the second experiment in our study indicated that when hatchlings entered a tyre rut they generally crawled along the rut, parallel to the shoreline. Again, this is more pronounced in the deeper ruts, where all but 1 (>99\%) hatchling did not escape from the $10 \mathrm{~cm}$ rut. However, when hatchlings encountered a $5 \mathrm{~cm}$ deep tyre rut, $47 \%$ crawled out of the rut within the $10 \mathrm{~min}$ time limit, generally within $1 \mathrm{~m}$ of the entry point. In other studies, loggerhead sea turtle hatchings also show a tendency to travel along 10 to $15 \mathrm{~cm}$ deep ruts rather than climbing through the obstacle (Hosier et al. 1981, Lamont et al. 2002). This would further increase exposure to predation, dehydration and energy consumption during the beach dispersal phase, and is particularly concerning, given that ORV ruts have previously been reported to run parallel to the shoreline for entire stretches of beaches (Hosier et al. 1981, van de Merwe \& Cuttriss 2006, Schlacher \& Thompson 2008).

The results of the present study indicate significant impacts of ORV ruts on the dispersal of green turtle hatchlings, and highlight the need to manage areas where recreational use of vehicles occurs on sea turtle nesting beaches. A potential solution for reducing the effects of ORV traffic on sea turtle hatchling dispersal may be to manually smooth the tyre ruts at the end of each day to ensure a relatively flat surface for hatchling dispersal at night. However, this would require considerable time and resources that may not be available in many sea turtle nesting areas. An alternative may be to restrict vehicle use to the harder sand near the tide mark, where ruts are generally much shallower and regularly washed over by tidal and wave movement (Hosier et al. 1981, Schlacher \& Thompson 2008). Certainly, the results from our study indicate that there is some ability for hatchlings to climb through the shallow ruts that are likely to occur in this section of the beach. When the ruts are $\geq 10 \mathrm{~cm}$ deep (typical of softer sand above the high-tide mark), hatchling dispersal is severely impeded. However, prior to any decisions restricting ORVs to the low-tide areas, the overlap of other species utilising the beach also needs to be considered. Given the high volume of macroinvertebrate species near the tide mark, concentrating traffic in this area may cause impacts (e.g. crushing disturbance) on other species (van der Merwe \& van der Merwe 1991, Schlacher \& Thompson 2008).

Consideration of the best management practices to control beach traffic presents many challenges. In some areas, beach driver education programs aimed at avoiding the high-tide mark areas seem futile, with a high magnitude of physical disturbance in these areas regardless of management attempts (Schlacher \& Thompson 2008). Active beach management restricting traffic volumes, seasons, or tides may also be impractical in many areas (Schlacher \& Thompson 2008). Given the potential impact of ORVs on endangered sea turtle hatchlings presented here and elsewhere (Hosier et al. 1981, Lamont et al. 2002), as well as the direct impacts on other species utilising the beach habitat (van der Merwe \& van der Merwe 1991), perhaps the best management practice from an environmental perspective is to prohibit ORVs on beaches completely. However, it is understood that this is not always possible due to social, cultural and economic demands (Schlacher \& Thompson 2008). There is, therefore, a need to develop management strategies that encompass environmental, social, cultural and economic issues, which are likely to be specific to each location. From the evidence presented in the current study, at the very least, management actions should be aimed at restricting ORV traffic to the hard sand close to the tide line during the sea turtle hatchling dispersal season, to ensure only shallow tyre ruts are left on the beaches. Although there would still be some increased exposure to predation, energy consumption and dehydration from crawling through these shallow ruts, this would at least reduce exposure to deeper ORV ruts that can impede hatchling dispersal completely.

Acknowledgements. We especially thank Ben and Jo Barr for their assistance in conducting the field components at Ma'Daerah, and Michael Arthur (Griffith University) for advice on statistical analyses. In addition, thanks to all the Department of Fisheries, Malaysia, staff that assisted with logistics in the field. All work was carried out under Malaysian Wildlife Permits (Fisheries Act 1985) held by K. Ibrahim, using protocols approved by the Griffith University Animal Ethics Committee (Approval Number EAS/04/ 04aec).

\section{LITERATURE CITED}

Ackerman RA (1997) The nest environment and the embryonic development of sea turtles. In: Lutz PL, Musick JA (eds) The biology of sea turtles. CRC Press, Washington, DC, p 83-106

Dial BE (1987) Energetics and performance during nest emergence and the hatchling frenzy in loggerhead sea turtles (Caretta caretta). Herpetologica 43:307-315

Hosier PE, Kochlar M, Thayer V (1981) Off-road vehicle and pedestrian track effects on the sea-approach of hatchling loggerhead turtles. Environ Conserv 8:158-161 
Ibrahim K, Hamann M, Schauble C, Kassim AR, Whittier JM (2004) An integrated approach to hatchery management: data from Peninsula Malaysia. In: Coyne MS, Clark RD (compilers) Proc 21st Annu Symp Sea turtle Biol Conserv. NOAA Technical Memorandum NMFS-SEFSC-528, Miami, FL, p 195

IUCN (International Union for Conservation of Nature) (2011) IUCN Red List of Threatened Species, Version 2011.1. Available at: www.redlist.org (accessed 6 October 2011)

Lamont MM, Percival HF, Colwell SV (2002) Influence of vehicle tracks on loggerhead hatchling seaward movement along a northwest Florida beach. Florida Field Naturalist 30:77-109

Miller JD (1985) Embryology of marine turtles. In: Gans C (ed) Biology of the Reptilia, Vol 14-Development A. John Wiley and Sons, New York, NY, p 269-328

Schauble C, Hamann M, Ibrahim K, Kassim AR, Whittier JM (2003) Monitoring hatchery success - What's worthwhile? In: Seminoff J (compilers) Proc 22nd Annu Symp Sea Turtle Biol Conserv. NOAA Tech Memo NMFSSEFSC-503, Miami, FL, p 116

Editorial responsibility: Matthew Godfrey,

Beaufort, North Carolina, USA
Schlacher TA, Thompson LMC (2007) Exposure of fauna to off-road vehicle (ORV) traffic on sandy beaches. Coast Manag 35:567-583

Schlacher TA, Thompson LMC (2008) Physical impacts caused by off-road vehicles to sandy beaches: spatial quantification of car tracks on an Australian barrier island. J Coast Res 24:234-242

Stancyk SE (1982) Non-human predators of sea turtles and their control. In: Bjorndal KA (ed) Biology and conservation of sea turtles. Smithsonian Institution Press, Washington, DC, p 139-152

van de Merwe JP, Cuttriss A (2006) South Stradbroke Island: 2005/2006 Marine Turtle Monitoring Program. Gold Coast City Council, Gold Coast

van der Merwe D, van der Merwe D (1991) Effects of offroad vehicles on the macrofauna of a sandy beach. S Afr J Sci 87:210-213

Wyneken J, Salmon M (1992) Frenzy and post-frenzy swimming activity in loggerhead, green and leatherback hatchling sea turtles. Copeia 1992:478-484

Zar JH (1999) Biostatistical analysis. Prentice Hall, Engelwood Cliffs, NJ

Submitted: January 24, 2012; Accepted: April 18, 2012

Proofs received from author(s): June 11, 2012 